\title{
Validation of the self-confidence scale of nursing care in urinary retention
}

\author{
Alessandra Mazzo ${ }^{1}$ \\ José Carlos Amado Martins² \\ Beatriz Maria Jorge ${ }^{3}$ \\ Rui Carlos Negrão Batista ${ }^{4}$ \\ Rodrigo Guimarães dos Santos Almeida ${ }^{3}$ \\ Fernando Manuel Dias Henriques ${ }^{5}$ \\ Verónica Rita Dias Coutinho ${ }^{4}$ \\ Isabel Amélia Costa Mendes ${ }^{6}$
}

Objective: to validate an instrument to measure self-confidence of nursing care in urinary retention. Methods: methodological research study, carried out after ethical approval. A Likertlike scale of 32 items related to nursing care in urinary retention was applied to students of the graduate nursing course. For instrument validation, analysis of the sample adequacy and main components, Varimax orthogonal rotation and internal consistency analyses were developed. Results: in a sample of 305 students, there was high correlation of all items with the total scale and Cronbach's alpha of 0.949. The scale items were divided into five factors with internal consistency: Factor 1 (0.890), Factor 2 (0.874), Factor 3 (0.868), Factor 4 (0.814) and Factor 5 (0.773), respectively. Conclusion: the scale meets the validity requirements, demonstrating potential for use in evaluation and research.

Descriptors: Urinary Retention; Nursing; Trust; Urinary Catheterization.

\footnotetext{
${ }^{1}$ PhD, Professor, Escola de Enfermagem de Ribeirão Preto, Universidade de São Paulo, PAHO/WHO Collaborating Centre for Nursing Research Development, Ribeirão Preto, SP, Brazil.

2 PhD, Professor, Escola Superior de Enfermagem de Coimbra, Coimbra, Portugal.

${ }^{3}$ Doctoral student, Escola de Enfermagem de Ribeirão Preto, Universidade de São Paulo, PAHO/WHO Collaborating Centre for Nursing Research Development, Ribeirão Preto, SP, Brazil.

${ }^{4} \mathrm{PhD}$, Adjunct Professor, Escola Superior de Enfermagem de Coimbra, Coimbra, Portugal.

5 MSc, Professor, Escola Superior de Enfermagem de Coimbra, Coimbra, Portugal.

6 PhD, Full Professor, Escola de Enfermagem de Ribeirão Preto, Universidade de São Paulo, PAHO/WHO Collaborating Centre for Nursing Research Development, Ribeirão Preto, SP, Brazil.
}

Corresponding Author: Alessandra Mazzo

Universidade de São Paulo. Escola de Enfermagem de Ribeirão Preto Departamento de Enfermagem Geral e Especializada

Av. Bandeirantes, 3900

Bairro: Monte Alegre

CEP: 14040-902, Ribeirão Preto, SP, Brasi

E-mail: amazzo@eerp.usp.br
Copyright () 2015 Revista Latino-Americana de Enfermagem This is an Open Access article distributed under the terms of the Creative Commons Attribution Non-Commercial License (CC BY-NC).

This license lets others distribute, remix, tweak, and build upon your work non-commercially, and although their new works must also acknowledge you and be non-commercial, they don't have to license their derivative works on the same terms. 


\section{Introduction}

Urinary Retention (UR) is defined as the accumulation of urine in the bladder that occurs due to the inability of this organ to void. The triggering factors of this problem may be related to obstruction of the urethra, motor and sensory changes, anxiety, drug effects, among others, often leading to the development of feelings of discomfort, increased sensitivity of the pubic symphysis and restlessness. In severe cases of UR, the patient collects more than $2,000 \mathrm{ml}$ of urine in the bladder due to the loss of secondary bladder tone or excessive stretching of the detrusor muscle fibers, which can lead to hypertonicity of the bladder, Urinary Tract Infections (UTI) and even the formation of kidney stones ${ }^{(1-2)}$.

The different aspects that involve nursing care in UR are part of the nurse and patient's daily clinical reality. In this matter, there are various possibilities for interventions, among which the most common are highlighted, such as the human and material resources; clinical evaluation measures, comfort, hygiene and performing of urinary catheterization, although not always carried out based on the best scientific evidence $^{(3-4)}$.

In the procedures related to clinical assessment of the patient with UR, the clinical history data collection and physical examination of the patient's bladder are emphasized.

The physical examination of the bladder is based on inspection, palpation and percussion, which are intended to identify texture changes, thickness, consistency, sensitivity, volume and hardness of the organ(5). It is a simple procedure, which may be characterized as extremely complex, since it involves subjectivity of the examiner, changes in the operational and clinical conditions of the patient (for example, changes due to the use of drugs and patient age $)^{(6)}$. Therefore, the use of portable bladder ultrasound is required, to be carried out with greater safety and precision.

The portable bladder ultrasound is a noninvasive method that allows the professional to diagnose the UR, evaluate the volume of urine in the bladder (preand/or post-voiding) and safely and with good level of confidence, opt for performing or not the urinary catheterization $^{(7-8)}$. However, the equipment is not widely used in clinical practice.

Urinary catheterization is one of the most common procedures of nursing care in urinary retention. It should be performed by nurses, with accuracy and scientific knowledge, transposing myths and practical rituals.
When performed improperly or because it is an invasive intervention, it can lead to several complications, among which stand out the Urinary Tract Infection (UTI), urethral trauma, pain and wrong urinary path ${ }^{(3-4,9)}$.

In this complex context, as in many other aspects of nursing care to the patient, capable and confident professionals are necessary so that nursing care in UR is performed with quality and safety to the patient.

Self-confidence is the possibility that an individual has to demonstrate belief in the success, capabilities and skills, in a given context(10). It must be achieved with wisdom, experience, success, support and training and, to be maintained, persistence, self-awareness and positive thinking are needed. As a result, it leads to stability of autonomy and positive results ${ }^{(11)}$.

Self-confidence is related to self-efficacy. It is the degree of conviction and success for achieving a result, acting decisively in the mode of action, behavior, organization, thought patterns and emotional reactions $^{(12-13)}$. It is a measure of self-perception and belief in one's own abilities ${ }^{(14)}$.

In nursing care for UR, nurses need to feel secure and confident regarding to their activities, generating a level of confidence for the patient and the health team, which positively compromises care $^{(15)}$. Therefore, it is essential to invest in personal qualification programs to develop the necessary attributes, focusing on knowledge weaknesses and professional training. Therefore, it is necessary to use instruments that aim for the evaluation procedures and target these actions.

In this context, this study aims to validate a selfconfidence scale of nursing care in urinary retention.

\section{Method}

This is a methodological research study, carried out with students from the $4^{\text {th }}$ and final year of the graduate nursing course of a public university of Portugal.

The Ethics Committee of the Unit of Research in Health-Nursing Sciences of the Nursing School of Coimbra (P 129-12/2012) and the National Research Ethics Commission in Brazil (CONEP 505.722/2013) approved the study. The students were invited to participate in the study. The anonymity and voluntary participation were maintained. A Free Informed Consent Form (IC) was used.

All 305 students invited were part of the sample, establishing a relation of 9.5 participants per item of the scale under consideration ${ }^{(16)}$. 
For the development of the instrument, previous studies addressing nursing care in urinary eliminations ${ }^{(3-4,17)}$ were used and a theoretical framework that deals with self-confidence ${ }^{(10-15)}$. Based on this material, a list of items was constructed called Self-Confidence Scale of Nursing Care in Urinary Retention (EAAERU).

The EAAERU consists of a list of 32 statements for which the respondent expresses his/her opinion in a Likert-like questionnaire of 5 points, in which (1) represents not confident, (2) little confident, (3) confident, (4) very confident and (5) completely confident. The list was constructed and validated, regarding its appearance and content, by researchers from Brazil and Portugal, according to the new Portuguese orthography and spelling rules. An interrater agreement index of $70.0 \%$ was considered. There was no disagreement among the participants on any item of the instrument in this process.

After obtaining the data, a database was developed using SPSS, version 22.

To determine the validity and reliability of the construct, descriptive statistics with central trend and dispersion (mean, mode, median, percentiles, variance, standard deviation) measures were used to characterize the sample and statistical inference (factor analysis and estimate of internal consistency). For the evaluation of the results, $\mathrm{p}<0.05$ was assumed as statistically significant.

\section{Results}

Among the 305 respondents, 268 (87.9\%) started the graduation course in 2009. The mean age was 22.1 years, ranging between 21 and 40 years. Most students (77.7\%) were between 21 and 22 years old, with a standard deviation of 2.40 . As to gender, 42 (13.8\%) were men and $263(86.2 \%)$ were women.

With regard to previous experiences of students with the subject addressed, 270 (88.5\%) reported to have already performed evaluation of patients with urinary retention, $34(11.1 \%)$ never performed and one $(0.3 \%)$ did not answer. As for performing urinary catheterization, 301 (98.7\%) reported that they had performed the procedure, three (1.0\%) had never performed it and one $(0.3 \%)$ did not answer.

\section{The EAAERU scale}

The scale showed a good suitability database, with a ratio of $9.5: 1$, with respect to the number of cases and its relationship with the quantity of variables.
Good linear association among the variables (with $68.0 \%$ of the correlations above 0.30 ) was observed by the use of the correlation matrix.

The Kaiser-Meyer-Olkin measure of sampling adequacy test showed good adequacy of the sample for analysis(18), with a value of 0.936 . Bartlett's test of sphericity achieved statistically significant values with $X^{2}=5690.762$ and $p<0.001$, which indicated the existence of relations among the variables that were expected to be included.

The anti-image matrix corroborates the sample suitability of each variable for using factor analysis, by presenting high values on the diagonal that range from 0.884 ("estimate by palpation the volume of urine in the bladder") to 0.967 ("fix the catheter as needed"), which suggests the inclusion of all variables for factor analysis.

To achieve the factors of the EAAERU, a factor analysis of the main components was carried out among the 32 items of the instrument, using the method of main components and Varimax orthogonal rotation.

After analysis and observation of the Scree Plot, it was possible to identify the proposed division of the items in four or five factors. Taking into account the construct, the sample size, the factor analysis, the Scree Plot convergence and the scale interval of five factors explained $61.0 \%$ of the variance. Therefore, it was decided to maintain the division of the scale into five factors, in the final analysis.

As shown in Table 1, after defining the five factors, the proportion of variance of each variable was verified, which were explained by the extracted components (commonalities) and factor loadings of each item. Due to the sample size, it was decided to keep the items with factor loading superior to $0.40^{(19)}$.

After carrying out the rotation and in view of a satisfactory factor solution, meanings were attributed to factors ${ }^{(20-21)}$. Thus, the EAAERU was divided into five factors, with the factor (composed by the 8 items 18 , $19,20,21,22,23,25,29)$ being called "interventions performed during urinary catheterization and/or in iatrogenic situations, "the factor 2 (composed by seven items: $10,11,12,13,14,15,16)$ and being called "Prior interventions to performing urinary catheterization", the factor 3 (composed by seven items: 24 26, 27, 28, 30, 31,32 ) and called "Interventions performed for urinary catheters", the factor 4 (composed by six items: 1,6 , 7, 8, 9 and 17) and called "Communication, consent and preparation of materials for performing urinary catheterization" and the factor 5 (composed by four items: 2, 3, 4 and 5) and called "Objective evaluation of UR". 
Regarding the analysis of the set of items that compose the EAAERU and its relationship with the construct, through the alpha Cronbach's test (Table 2), thereby testing the proposed items and their mutual correlation, high correlation of all items with the full scale was achieved, resulting in a high alpha value (0.949). It was found that all items contributed to the good alpha coefficient, undermining the scale if either of them is eliminated.

After analysis of the global coefficient, the coefficients of the EAAERU with each dimension remained high, indicating good consistency. Cronbach's alpha values were: Factor 1 (0.890), Factor 2 (0.874), Factor 3 (0.868), Factor 4 (0.814) and Factor 5 (0.773).
Due to the impossibility of applying the EAAERU in an entirely new sample, dividing the sample into two sub-samples (sample A and sample B) was considered, which were obtained by randomization feature of the samples, provided by SPSS. In all subsamples analyzed, the tests performed on this sample were replicated and similar results were found with regard to the reliability of the scale (Cronbach's alpha of subsample A was of 0.944 and of 0.951 for subsample $B)$, considered a good correlation and division of the scale into five factors.

The descriptive results of the EAAERU are shown in Table 3.

Table 1 - Correlation matrix of the items of the factors rotated by Varimax, with Keiser normalization for five factors $(\mathrm{N}=305)$. Coimbra, Portugal, 2014

\begin{tabular}{|c|c|c|c|c|c|}
\hline \multirow{2}{*}{ Items } & \multicolumn{5}{|c|}{ Factors } \\
\hline & 1 & 2 & 3 & 4 & 5 \\
\hline Listen the complaint & & & & 0.535 & \\
\hline Evaluate the patient ... & & & & & 0.720 \\
\hline Palpate the bladder & & & & & 0.717 \\
\hline Estimate, by palpation.... & & & & & 0.735 \\
\hline Decide on the catheterization & & & & & 0.527 \\
\hline Material... intimate hygiene & & & 0.407 & 0.520 & \\
\hline Material... procedure & & & 0.410 & 0.588 & \\
\hline Communicate... & & & & 0.669 & \\
\hline Obtain consent .... & & & & 0.610 & \\
\hline Ensure privacy.... & & 0.688 & & & \\
\hline Ensure biosafety ... & & 0.673 & & & \\
\hline Perform handwashing & & 0.764 & & & \\
\hline Perform personal hygiene ... & & 0.746 & & & \\
\hline Open the material & & 0.680 & & & \\
\hline Define the level of aseptic ... & & 0.580 & & & \\
\hline Perform antisepsis of the perineum & & 0.539 & & & \\
\hline Decide whether or not lubricating $\ldots$ & & & & 0.410 & \\
\hline Inserting the probe ... & 0.536 & & & & \\
\hline Define the length ... & 0.568 & & & & \\
\hline Collection bag ... & 0.509 & & & & \\
\hline Intervene there is no drainage .... & 0.686 & & & & \\
\hline Intervene there is hematuria ... & 0.659 & & & & \\
\hline Decide resistance to progression ... & 0.739 & & & & \\
\hline Fix the catheter ... & & & 0.495 & & \\
\hline Intervene... if there is disconnection ... & 0.557 & & & & \\
\hline Perform the urine collection ... & & & 0.592 & & \\
\hline Evaluate the urine volume ... & & & 0.449 & & \\
\hline Evaluate ... collection bag & & & 0.651 & & \\
\hline Decide when to remove catheter & 0.552 & & & & \\
\hline Give destination to the material ... & & & 0.757 & & \\
\hline Register ... & & & 0.719 & & \\
\hline Evaluation of patient after ... & & & 0.683 & & \\
\hline
\end{tabular}


Table 2 - Statistics of homogeneity of the items and Cronbach's internal consistency coefficient of the EAAERU in its entirety $(\mathrm{N}=305)$. Coimbra, Portugal, 2014

\begin{tabular}{|c|c|c|c|c|}
\hline Items & Average & Standard Deviation & Correlation with the Total (adjusted) & Alpha if the item is removed \\
\hline 1 & 4.42 & 0.662 & 0.456 & 0.949 \\
\hline 2 & 3.62 & 0.645 & 0.482 & 0.949 \\
\hline 3 & 3.84 & 0.760 & 0.508 & 0.949 \\
\hline 4 & 2.77 & 0.878 & 0.399 & 0.950 \\
\hline 5 & 3.39 & 0.771 & 0.610 & 0.948 \\
\hline 6 & 4.52 & 0.598 & 0.596 & 0.948 \\
\hline 7 & 4.54 & 0.590 & 0.658 & 0.947 \\
\hline 8 & 4.28 & 0.657 & 0.565 & 0.948 \\
\hline 9 & 4.30 & 0.667 & 0.526 & 0.948 \\
\hline 10 & 4.71 & 0.487 & 0.472 & 0.949 \\
\hline 11 & 4.45 & 0.602 & 0.547 & 0.948 \\
\hline 12 & 4.83 & 0.397 & 0.518 & 0.949 \\
\hline 13 & 4.65 & 0.535 & 0.589 & 0.948 \\
\hline 14 & 4.60 & 0.599 & 0.660 & 0.947 \\
\hline 15 & 4.43 & 0.638 & 0.613 & 0.948 \\
\hline 16 & 4.40 & 0.670 & 0.682 & 0.947 \\
\hline 17 & 4.40 & 0.736 & 0.610 & 0.948 \\
\hline 18 & 4.18 & 0.731 & 0.709 & 0.947 \\
\hline 19 & 3.96 & 0.789 & 0.639 & 0.947 \\
\hline 20 & 4.15 & 0.770 & 0.639 & 0.947 \\
\hline 21 & 3.41 & 0.871 & 0.626 & 0.948 \\
\hline 22 & 3.31 & 0.839 & 0.663 & 0.947 \\
\hline 23 & 3.29 & 0.816 & 0.618 & 0.948 \\
\hline 24 & 4.23 & 0.707 & 0.656 & 0.947 \\
\hline 25 & 3.97 & 0.787 & 0.658 & 0.947 \\
\hline 26 & 4.05 & 0.755 & 0.577 & 0.948 \\
\hline 27 & 3.96 & 0.866 & 0.528 & 0.949 \\
\hline 28 & 4.33 & 0.710 & 0.674 & 0.947 \\
\hline 29 & 3.80 & 0.835 & 0.691 & 0.947 \\
\hline 30 & 4.55 & 0.628 & 0.639 & 0.947 \\
\hline 31 & 4.49 & 0.615 & 0.639 & 0.947 \\
\hline 32 & 4.34 & 0.654 & 0.703 & 0.947 \\
\hline
\end{tabular}

Table 3 - Descriptive statistics for each dimension and the total scale. Coimbra, Portugal, 2014

\begin{tabular}{lccccc}
\hline & Factor $\mathbf{1}$ & Factor $\mathbf{2}$ & Factor $\mathbf{3}$ & Factor $\mathbf{4}$ & Factor $\mathbf{5}$ \\
\hline Average & 3.76 & 4.58 & 4.28 & 4.40 & 3.40 \\
Median & 3.75 & 4.71 & 4.28 & 4.50 & 3.50 \\
Mode & 4.00 & 5.00 & 4.86 & 4.83 & 3.75 \\
Standard Deviation & 0.606 & 0.430 & 0.532 & 0.471 & 0.592 \\
Variance & 1.63 & 3.00 & 2.71 & 2.83 & 1.25 \\
Minimum & 5.00 & 5.00 & 5.00 & 4.00 & 5.00 \\
Maximum & 3.76 & 4.58 & 4.28 & & 3.408 \\
Percentiles & & & 4.16 & 3.00 \\
25 & 3.37 & 4.28 & 4.00 & 4.50 & 3.50 \\
50 & 3.75 & 4.71 & 4.28 & & 3.75 \\
75 & 4.25 & 5.00 & & & \\
\hline
\end{tabular}

\section{Discussion}

Urinary elimination is one of the basic needs of individuals(22), often affected in the processes of health/ disease, which makes it one of the focuses of nursing interventions. In the proceedings on urinary elimination problems, one of the nursing diagnoses commonly found is the Urinary Retention.

In many nursing work contexts(23), which includes nursing care in Urinary Retention, interventions should 
be performed with quality, safety and comfort, both for the patient and the professional. It is achieved by incorporating updated scientific and technical knowledge and the best scientific evidence into clinical practice, which leads to the constant need for training of professionals as well as scientific update of educational institutions focused on their training.

Well-trained professionals will be more confident and efficient, better performing their functions, with less stress, greater motivation, persistence and expectation of success ${ }^{(24)}$. The failure can cause discouragement and obstacles to achieve objectives. In this sense, it is necessary to know the possibilities and limitations for the development of new skills and new achievements ${ }^{(25)}$.

In this context, due to the need and the lack of an instrument to investigate and evaluate the confidence of nurses in nursing care of Urinary Retention, the EAAERU was proposed. After the construct validation, a high correlation of all items with the total scale was observed with a good reliability index (alpha $=0.949$ ), indicating that the scale measures the self-confidence of nursing care in urinary retention.

By means of factor analysis and statistical support, it was possible to identify the division of the scale into five factors, represented by 1 ) "Interventions performed during urinary catheterization and/or iatrogenic situations", 2) "Previous interventions to performing urinary catheterization" 3) "Interventions performed after urinary catheterization"; 4) "Communication, consent and preparation of materials for performing urinary catheterization" and 5) "Objective evaluation of UR", which showed good reliability indices, contributing to internal consistency. The factor that showed the lowest reliability index is composed of few items $(2,3,4$ and 5 ) and had an objective assessment of UR (Cronbach's alpha of 0.773 ).

The descriptive values of the sample showed that students were more confident in carrying out measures related to communication, consent, preparation of the material, patient and professional (factor 2, factor 4) and after catheter removal (factor 3 ) and less confident regarding the problem situations and in the objective assessment of UR (factor 1 and factor 5). These results corroborate the studies of several authors, which points out the difficulties of the objective assessment of UR and problem factors related to trauma to catheter insertion for delayed urinary catheterization as the main difficulties presented by the professionals(22). These findings stimulate the incorporation of scientific evidence into clinical practice and use of existing and little disseminated technological resources, such as the portable ultrasound of bladder.

The fact that the validation of EAAERU initially has been accomplished in one Portuguese-speaking country only can be mentioned as a limiting factor, although it has been developed according to the new orthography and spelling rules, and adopted by professionals from Portuguese-speaking countries. It is considered that the developed instrument can be applied to professionals. However, it is recommended that statistical tests be repeated during the process, since the validation process occurred with the finalyear students of the nursing graduate course, mostly with experience in the subject.

\section{Conclusion}

The use of consistent instruments that enable the assessment of nursing professionals, aiming at the better targeting of training processes, is extremely important in the clinical practice of nurses, since they stimulate and incorporate scientific evidence into the professional training process, providing greater safety, quality and comfort to the patients and professionals.

The process of care for the patient with urinary retention is part of the clinical everyday. In this sense, the validation for the Portuguese language of the EAAERU scale was proposed, to assess the confidence on this subject, according to the new spelling rules. In the study population, the EAAERU showed good psychometric properties, which indicates its use for teaching activities and for professional training throughout life, as well as for research.

\section{References}

1. Peng CW, Chen JJ, Cheng CL, Grill WM. Improved bladder emptying in urinary retention by electrical stimulation of pudendal afferents. J Neural Eng. 2008 Jun;5(2):144-54.

2. Fernandes MCBC, Costa VV, Saraiva RA. Postoperative urinary retention: evaluation of patients using opioids analgesic. Rev. Latino-Am. Enfermagem. 2007 Apr; 15(2):318-22.

3. Mazzo A, Gaspar AACS, Mendes IAC, Trevizan MA, Godoy S, Martins JCA. Urinary catheter: Myths and rituals present in preparation of patients. Acta Paul Enferm. 2012;25(6):889-94.

4. Mazzo A, Godoy S, Alves LM, Mendes IAC, Trevizan MA, Rangel EML. Urinary catheterization: facilities and 
difficulties related to its standardization. Texto Contexto Enferm. 2011 Jun; 20(2):333-9.

5. Bickley LS, Szilagyi PG. Bates' Guide to Physical Examination and History Taking. Philadelphia: Lippincott Williams \& Wilkins; 2012.

6. Palese A, Buchini S, Deroma L, Barbone F. The effectiveness of the ultrasound bladder scanner in reducing urinary tract infections: a meta- analysis. J Clin Nurs. 2010;19(21-22):2970-9.

7. Gould CV, Umscheid CA, Agarwal RK, Kuntz G, Pegues DA; Healthcare Infection Control Practices Advisory Committee. Guideline for prevention of catheterassociated urinary tract infections 2009. Infect Control Hosp Epidemiol. 2010 Apr;31(4):319-26.

8. Balderi T, Mistraletti G, D'Angelo E, Carli F. Incidence of postoperative urinary retention (POUR) after joint arthroplasty and management using ultrasoundguided bladder catheterization. Minerva Anestesiol. 2011;77(11):1050-7.

9. Ministério da Saúde (BR). Conselho Federal de Enfermagem. Resolução COFEN n.450, de 11 de dezembro de 2013. Normatiza o procedimento de Sondagem Vesical no âmbito do Sistema Cofen / Conselhos Regionais de Enfermagem. Diário Oficial da União, Brasília (DF); 27 dez 2013; Seção 1:305.

10. Perry P. Concept analysis: confidence/selfconfidence. Nurs Forum. 2011 Oct-Dec;46(4):218-30.

11. White KA. Self-confidence: A concept analysis. Nurs Forum. 2009 Apr-Jun;44(2): 103-14.

12. Bandura A. Perceived self-efficacy in cognitive development and functioning. Educ Psychol. $1993 ; 28(2): 117-48$.

13. Bandura A. Self-efficacy in changing societies. New York: Cambridge University Press; 1995.

14. Bandura A. Social foundations of thought and action: A social cognitive theory. Englewood Cliffs (NJ): Prentice Hall; 1986.

15. Kröner $S$, Biermann A. The relationship between confidence and self- concept- Towards a model of response confidence. Intelligence. 2007 NovDec;35(6):580-90.

16. Hair JF Jr, Anderson RE, Tatham RL, Black WC. Análise multivariada de dados. 5ed. Bookman: Porto Alegre; 2005.

17. Mazzo A, Beltreschi CB, Jorge BM, Souza VD Jr, Fumincelli L, Mendes IAC. Cateterismo urinário permanente: práctica clínica. Enferm Global. Forthcoming. 2015

18. Pestana MH, Gageiro JN. Análise de Dados para Ciências Sociais: A complementaridade do SPSS. 3ed. Lisboa: Sílabo; 2005.
19. Hair Jr JF, Black WC, Babin BJ, Anderson RE. Multivariate Data Analysis. 7th ed. Upper Saddle River: Prentice Hall; 2010.

20. Field A. Discovering Statistics Using SPSS. 3rd ed. Londres: Sage; 2009.

21. Laros JA. O uso da análise fatorial: algumas diretrizes para pesquisadores. In: Pasquali $L$, editor. Análise fatorial para pesquisadores. Brasília: LabPAM; 2005. p. 163-84.

22. Mundy AR, Andrich DE. Urethral trauma. Part I: Introduction, history, anatomy, pathology, assessment and emergency management. BJU Int. 2011 Aug;108(3):310-27.

23. Horta WA. Processo de enfermagem. São Paulo (SP): EPU; 1979.

24. Bandura A. Human agency in social cognitive theory. Am Psychol. 1989;44(9):1175-84.

25. Barreira DD, Nakamura AP. Resiliência e a autoeficácia percebida: articulação entre conceitos. Aletheia. 2006 Jun;(23):75-80. 